\title{
Fabrication of Electrochemical Sensor for Hyaluronic Acid Determination
}

Chen Chen, Junfang Li, Xiaoli Bai, Ke Pei, Mingyue Wang, Hongqiao Zhao, Linlin Yang and Caie Wang

Department of Clinical Pharmacy, the First Affiliated Hospital of Henan University of Science and Technology P.R. China

*E-mail: wangcaie890@ sohu.com

doi: $10.20964 / 2017.08 .38$

Received: 15 April 2017 / Accepted: 2 June 2017 / Published: 12 July 2017

This work employed a facile one-pot hydrothermal method to prepare a reduced graphene oxide- $\mathrm{ZnO}$ nanorods composite (RGO-ZnO). Glassy carbon electrode (GCE) was modified by the obtained nanocomposite, which was then used to realize the selective and sensitive detection of hyaluronan (HY). The fabricated biosensor was linearly related to HY concentration $(1-800 \mu \mathrm{M})$, with a limit of detection (LOD) of $0.42 \mu \mathrm{M}(\mathrm{S} / \mathrm{N}=3)$. This biosensor for $\mathrm{HY}$ was stable, reproducible and characteristic of anti-interference. Furthermore, the proposed biosensor has potential for further application in HY detection in gecko extract specimens.

Keywords: Electrochemical sensor; Graphene; Zinc oxide; Hyaluronan; Gecko extract

\section{$\underline{\text { FULL TEXT }}$}

(C) 2017 The Authors. Published by ESG (www.electrochemsci.org). This article is an open access article distributed under the terms and conditions of the Creative Commons Attribution license (http://creativecommons.org/licenses/by/4.0/). 